


\title{
LAS CONCEPCIONES TRIBUTARIAS DEL LIBERALISMO CLASICO*
}

THE TRIBUTARY CONCEPTIONS OF THE CLASSICAL LIBERALISM

\section{AS CONCEIÇÕES TRIBUTARIAS DO LIBERALISMO CLASSICO}

\author{
OSCAR RAMIREZ CARDONA*:
}

\author{
Universidad de los Andes \\ Recibido: 18-08-2009. Aceptado: 30-11-2009 \\ "Entre las artes del gobierno ninguna se aprende tan presto como la de sacar el dinero del \\ bolsillo de los contribuyentes".
}

Adam Smith

\section{RESUMEN}

El presente documento pretende mostrar las concepciones fiscales que surgen a partir de las ideas políticas y económicas del liberalismo clásico, establecer las relaciones que pueden darse entre los tributos recomendados o considerados adecuados para esta escuela y su particular visión del Estado y de los órganos del poder público. Expone la confluencia de las concepciones políticas y económicas y cómo las instituciones fiscales resultan igualmente importantes para los teóricos políticos de esta corriente del pensamiento.

\section{PALABRAS CLAVE}

Estado de naturaleza, contrato social, ramas del poder, propiedad privada, valor de uso, valor de cambio, comercio internacional, impuesto sobre la renta, impuesto sobre la tierra, impuesto sobre las casas, impuesto sobre las utilidades, impuestos sobre el salario, diezmos.

\section{ABSTRACT}

The purpose of this document is to show the fiscal notions that surface from the classical liberalism political and economical ideas, to establish the relations between the taxes viewed most convenient for this school and its particular conceptions about the State and the power branches. Here it is illustrated the confluence of political and economical conceptions and how the fiscal institutions became as important to political thinkers as to economical ones.

\section{KEY WORDS}

States of nature, social contract, power branches, private property, value in use, value in exchange, foreign trade, tax on rent, land tax, taxes on houses, taxes on profits, taxes on wages, tithes.

\footnotetext{
* Este documento hace parte de la línea de investigación del trabajo con el cual el autor obtuvo su grado de Magíster en Derecho, de la Universidad de los Andes.

** Abogado de la Universidad Santo Tomás de Bogotá, Magíster en Derecho de la Universidad de los Andes, especialista en Derecho Tributario de la Universidad del Rosario y en Legislación Financiera de la Universidad de los Andes. Ha sido profesor de Posgrado en las Universidades del Rosario, La Gran Colombia, Externado y Los Andes.
} 


\section{RESUMO}

O presente documento pretende mostrar as conceições fiscais que surgem a partir das idéias políticas e econômicas do liberalismo clássico, estabelecer as relações que se podem dar entre os tributos recomendados ou considerados adequados para esta escola e sua particular visão do Estado e dos órgãos do poder público. Expõe a confluência das conceições políticas e econômicas e como as instituições fiscais resultam igualmente importantes para os teóricos políticos desta corrente do pensamento.

\section{PALAVRAS CHAVE}

Estado de natureza, contrato social, ramas do poder, propriedade privada, valor do uso, valor do cambio, comercio internacional, ônus sobre renda, ônus sobre as casas, ônus sobre as utilidades, ônus sobre o ordenado, dízimos.

\section{INTRODUCCION}

En tiempos de crisis económica el debate sobre los modelos se intensifica: ¿Fracasó el neoliberalismo? ¿El tiempo le ha dado la razón a Keynes? ¿Confirman su validez las ideas marxistas sobre el Estado y la economía? Y dentro de este debate, no juega un papel menos importante el tema fiscal, el modelo tributario. Se afirma que se ha dado un papel preponderante a la imposición indirecta sobre la directa, que en el caso concreto colombiano se ha privilegiado el gran capital con importantes exenciones en materia del impuesto sobre la renta, lo que aumenta el déficit fiscal sin lograr los supuestos beneficios de incremento de la productividad, la inversión y el empleo, pero por sobre todo sin que el "bienestar" de los favorecidos con las medidas alcance a los demás grupos sociales. Se cuestiona si en el momento actual en el que la fórmula pareciera ser el incremento del consumo, resulta conveniente conservar o profundizar un sistema fiscal que propenda a más impuestos indirectos y mayor imposición a la clase media a través del impuesto a la renta.

\section{PROBLEMA DE INVESTIGACION}

El contexto existente justifica el intento de realizar un recuento histórico que permita dilucidar cuál ha sido la posición de las diferentes escuelas político-económicas en cuanto a los impuestos, su justificación y su función conforme a la concepción del Estado y de los órganos de poder.

El presente escrito se centra en el análisis de lo que se ha denominado el liberalismo clásico que comprende la corriente política y económica que florece en los siglos XVII y XVIII. En relación con esta escuela de pensamiento puntualizaremos la función del Estado, el papel de los impuestos y la relación de estos con las diferentes ramas del poder público.

\section{METODOLOGIA}

Desde la corriente política1 se analizarán las obras de John Locke, pensador inglés que padeció personalmente las perplejidades del autoritarismo y del barón de Montesquieu, agudo escrutador de las realidades sociales, autores ambos que desde sus personales experiencias

1 En el presente escrito utilizaré la expresión "los políticos", para referirme a aquellos pensadores que conciben al Estado como el escenario principal y primario de las relaciones sociales, constituyéndose por tanto en el objeto de su estudio. La expresión "los economistas" será utilizada para hacer mención a aquellos pensadores para quienes el "mercado" es visto como un escenario fundamental en las relaciones sociales a partir del cual podrían explicarse, justificarse y descartarse incluso las organizaciones políticas. 
son precursores de la teoría de la división del poder público. En las obras que se analizan Locke y Montesquieu hacen referencia a la función impositiva del Estado?

En cuanto a la corriente económica, las figuras más célebres son los escritores ingleses Adam Smith y David Ricardo. El primero, formado en la filosofía, profesor universitario y funcionario público, considerado el padre de la economía como ciencia autónoma. El segundo, agente de bolsa exitoso que gracias a sus buenos negocios pudo consagrarse al estudio de la economía, de las ciencias naturales y en forma residual a la actividad política como miembro de la cámara inglesa de los comunes.

Ambos autores dedicaron una parte importante de sus escritos más célebres ${ }^{3}$ al estudio de los impuestos, no como un elemento aislado de su análisis, sino como parte integral de sus concepciones económicas.

\section{RESULTADOS}

\section{EL PAPEL DEL ESTADO Y LAS RAMAS DEL PODER PUBLICO}

Elemento fundamental de las teorías políticas y económicas es su concepción sobre la razón del ser del Estado y de las diferentes ramas que lo conforman en la organización social. En forma simplista pudiera hablarse de Estado interventor o de Estado no interventor, pero considero que el Estado por naturaleza siempre interviene, por lo que las diferencias estriban más bien en el grado, la forma o los ámbitos de intervención y en el papel que se da al individuo o a la comunidad en las decisiones políticas o económicas.

Cuando hablo de liberalismo clásico quiero hacer referencia a aquella corriente que desde la perspectiva económica prohíja el papel fundamental del individuo y de las fuerzas del mercado para promover el interés público; desde el punto de vista político propende a la limitación al abuso del poder por parte del ejecutivo, para la época fundamentalmente en cabeza del monarca y por el establecimiento de contrapoderes (checks and balances) dentro del Estado. Pareciera que mientras que para los economistas la libertad y la propiedad son un medio, para los políticos son un fin.

Con base en las anteriores premisas, he escogido los autores citados en el aparte precedente por considerar que son los representantes más esclarecidos de escuela analizada.

\section{LOS POLITICOS}

1.1. John Locke, durante varios años médico personal, consejero y hombre de confianza del Conde de Shaftesbury, padeció la inestabilidad política de su protector, con quien compartiera la oposición a las actitudes autoritarias de la Corona, la defensa de la tolerancia religiosa y de los derechos de la cámara de los comunes como una forma de limitación al poder real, viéndose ambos, por estas posiciones, compelidos al exilio.

Precisamente, el exilio holandés permitiría que viera la luz el escritor y filósofo. En 1687 es publicado en Holanda por primera vez unos de sus escritos y es allí donde prepara "El ensayo sobre el gobierno civil" que fue publicado en forma anónima en Inglaterra en 1690.

El ensayo es, ante todo, un discurso contra el Leviatán, contra la justificación divina o contractual del absolutismo.

2 Concerning Civil Government, Second Essay de John Locke y Del espíritu de las leyes de Carlos Luis de Montesquieu.

3 "Investigación sobre la naturaleza y causas de la riqueza de las naciones" de Adam Smith (Libro V, Capítulo II, Parte II) y "Principios de economía política y tributación" de David Ricardo (Capítulo VIII a XVIII). 


\section{MISION JURIDICA}

ISSN 1794 -6OOXX NUMERO
enero - diciembre de 2009 ?

El poder del rey no es la natural derivación del poder paterno, ni del mandato divino, sino fruto del consentimiento de hombres libres en su estado de naturaleza ${ }^{4}$.

Sostiene Locke que el hombre en el estado de naturaleza es libre, dueño absoluto de su persona y de sus posesiones, igual a los más grandes y no sujeto a nadie, pero que el disfrute de tales prerrogativas está sujeto a la incertidumbre y expuesto a la invasión de otros, lo que hace su propiedad insegura y el disfrute de su libertad incierto. ${ }^{5}$

En el estado de naturaleza son deseables leyes conocidas por todos, que establezcan lo correcto y lo incorrecto por consenso común; jueces conocidos e imparciales que puedan resolver las diferencias de acuerdo con la ley establecida y un poder que respalde las decisiones de los jueces y las haga efectivas. Sin embargo, por diversas circunstancias estos ideales no siempre son realizables, razón por la cual los hombres aceptan renunciar a los privilegios y poderes de los cuales están investidos en el estado de naturaleza (de actuación y de castigo) con el fin de preservarse a sí mismos y a la humanidad. En últimas, los hombres se unen en el estado de sociedad y aceptan ser gobernados para conservar su libertad y su propiedad ${ }^{6}$.

El poder supremo del hombre en el estado de naturaleza es el legislativo, por ello la primera y fundamental ley en el estado de sociedad hace referencia al establecimiento del poder legislativo que, dependiendo de las manos en que se radique, permitirá hablar de una forma de gobierno democrática, oligárquica o monárquica. Cualesquiera que sea la forma de gobierno establecida, el poder legislativo y el ejecutivo deben estar en diferentes manos, el segundo debe estar subordinado al primero, y este, como poder fiduciario para el logro de los fines de estado de sociedad permanece siempre en el pueblo, quien retiene el poder supremo de salvarse a sí mismo de los actos que atenten contra su libertad y propiedades aun cuando provengan del mismo legislativo?.

De todas maneras, el poder ejecutivo por su calidad y la naturaleza de sus funciones y en procura del bienestar de la sociedad, posee ciertas prerrogativas que le permiten actuar en ausencia de norma legal e incluso en contra de ella. Lo anterior por cuanto el legislativo que no es permanente, y es conveniente que no lo sea, no puede precaver todas las situaciones que se presentan en las relaciones entre los asociados. Por otra parte, la adopción de las leyes a veces es demorada y su rígida aplicación puede causar, en ciertas circunstancias, más daño que bienestar.

Locke, a pesar de formular como una de las preocupaciones de los hombres en el estado de naturaleza la necesidad de un juez conocido que, con fundamento en leyes establecidas, resuelva los conflictos que puedan presentarse entre ellos, no considera a los jueces como un poder independiente, situación que puede explicarse en el contexto histórico inglés, en el que el ejercicio de la jurisdicción es una prerrogativa tanto del ejecutivo como del legislativo. En forma adicional a las funciones del Estado atrás indicadas, compete a este el empleo de la fuerza de la comunidad: en su interior solamente para procurar de la aplicación de las leyes, y en las fronteras para prevenir los daños foráneos o la invasión externa.

4 "Thus we may see how probable it is that people that were naturally free, and by their own consent, Esther submitted to the government of their father, or united together, out of different families, to make a government, should generally put the rule into one man's hands, and choose to be under the conduct of a single person, without so much, as by express conditions, limiting or regulating his power, which they thought safe enough in his honesty and prudence; though they never dreamed of monarchy being jure Divine, which we never heard of among mankind till it was revealed to us by the divinity of this last age, nor ever allowed paternal power to have a right to dominion or to be the foundation of all government". Concerning civil Government, John Locke, Great Books of the Western World, Encyclopedia Britannica, Inc. 33, 1991, pág. 51.

5 Ob. cit., p. 53.

6 Ob. cit., p. 54.

7 Ob. cit., p. 59. 
Importa destacar aquí, para los propósitos de este estudio, que la división de poderes es para Locke una garantía contra el autoritarismo y el absolutismo, el mecanismo ideal para preservar los derechos naturales a la libertad y la propiedad. Es decir, se acepta la necesidad del Estado, pero se da preeminencia al individuo. Es por ello que si la división de poderes no resulta suficiente para los fines que llevan a los individuos al estado de sociedad, pueden echar mano de los derechos naturales que les permiten sobreponerse al poder político.

Resultan igualmente importantes las apreciaciones económicas de Locke con gran incidencia en sus postulados políticos y que constituyen un destacado antecedente de las teorías fundamentales de los economistas clásicos a quienes haremos referencia más adelante ${ }^{8}$.

En primer lugar, está la concepción de la propiedad, la cual justifica por el trabajo. Dios dio a la humanidad el mundo en común, pero también le dio la propiedad sobre sí mismo y el mandato de trabajar, por lo que el producto del trabajo de su cuerpo, de sus manos, es propiamente suyo. El hombre actúa sobre las cosas para satisfacer sus necesidades, para atender a su subsistencia y a través del trabajo que despliega sobre ellas, pone algo de sí mismo que no es común a todos y que, por tanto, hace que devengan suyas, las convierte en su propiedad.

Siendo los bienes terrenales suficientes para satisfacer las necesidades humanas, cada quien puede hacerse propietario a través de su trabajo, haciendo suyo lo que requiere para su subsistencia en forma proporcionada y sin causar daño a los demás. Es normal que ello sucediera así en un principio, por cuanto siendo perecederas las cosas necesarias para la subsistencia del hombre, no podía este, sin perjuicio de los demás, tener más de aquellas que pudiera consumir. El valor de las cosas estaba determinado entonces por el "valor de uso", criterio tan importante para la economía clásica.

Con el transcurso del tiempo, las cosas del mundo, necesarias para la subsistencia del hombre son cada vez más producto de su industria, razón por la cual va a ser el trabajo el que determine de manera fundamental el valor de las cosas. Se encuentra así esbozada la teoría del valortrabajo de Smith y Ricardo ${ }^{10}$.

El trabajo concebido como el título de propiedad sobre las cosas comunes por naturaleza no da lugar a controversias. El derecho y la conveniencia van juntos, lo que corresponde a cada cual puede ser fácilmente determinable.

Esta situación cambia cuando el hombre por convención decide dar valor a ciertos bienes de casi ninguna utilidad para su vida (como el oro y la plata) permitiendo de esta forma la desproporcionada e inequitativa posesión de los bienes terrenales.

Las teorías del valor-trabajo y del trabajo-propiedad son un instrumento poderoso de limitación del poder real. La propiedad no es ya un atributo del monarca, quien la dispensa como concesión graciosa a sus súbditos, sino un derecho otorgado por el mismo Dios a todos los seres humanos y al cual se hacen acreedores a partir del trabajo. La propiedad es un concepto abierto e inclusivo que comprende por igual la vida, libertad y bienes, respecto de la cual el hombre tiene por naturaleza no solo el poder de protección contra los ataques de terceros,

8 Debemos destacar la vinculación que tuvo Locke con actividades y organismos de regulación económica en su país: se desempeñó como secretario del consejo de comercio en 1672 cuando el conde Shaftesbury fue Lord Canciller y en los últimos años de su vida fue funcionario de la junta de comercio creada por el gobierno de Guillermo de Orange, participando como asesor en temas de importancia económica como la acuñación de moneda y el establecimiento de un sistema efectivo de crédito a través del Banco de Inglaterra. Adicionalmente, realizó varios escritos de carácter económico como "Observations on silver money" y "Further considerations on raising de value of money".

9 Ob. cit., p. 33.

10 "... for it is labour indeed that puts the difference of value on everything;...". Locke, ob. cit., pág. 33. Adam Smith afirma por su parte que "Parece, pues evidente, que el trabajo es la medida universal y más exacta del valor, la única regla que nos permite comparar los valores de las diferentes mercancías en distintos tiempos y lugares. Investigación sobre la naturaleza y causas de la riqueza de las naciones. 9a. Fondo de Cultura Económica, pág. 37. 


\section{MISION JURIDICA}

A DEN $1794-600 \times$ NUMMERO
ISTero - diciembre de 2009

sino también, la facultad de juzgamiento y castigo cuando se produce su quebrantamiento. En estas circunstancias, la finalidad del gobierno, que el mismo hombre establece en el estado de sociedad, se circunscribe a la salvaguarda del derecho de propiedad y de los que lo comprenden, y a dirimir los conflictos que puedan presentarse como consecuencia de su ejercicio ${ }^{11}$.

1.2. El Barón de la Brède y Montequieu, profundo estudioso de la historia y agudo observador de los seres humanos, realiza en su obra Del espíritu de las leyes una detallada disección de las instituciones políticas que han regido las relaciones sociales a través del tiempo. Más que la obra de un filósofo, el trabajo de Montesquieu presagia los estudios sociológicos en los que factores otrora insospechados como el clima, modelan el comportamiento del individuo y de las organizaciones que crea para su convivencia.

Las formas de gobierno que tiene el hombre no son fruto del azar, cada una de ellas tiene una naturaleza y obedece a unos principios. Las leyes surgen de la naturaleza del gobierno y se relacionan con tales principios. Así, es de la naturaleza del gobierno republicano el que el poder soberano resida en el todo pueblo (democracia) o en parte de él (aristocracia); en el gobierno monárquico uno solo gobierna pero con sujeción a leyes fijas y preestablecidas; en el despótico gobierna igualmente uno sólo pero sin ley ni regla ${ }^{12}$. A cada forma de gobierno corresponden unos principios que son como su fuerza, lo que les permite obrar, mientras que su naturaleza es lo que les permite ser. El principio de la república es la virtud, el de la monarquía es la moderación y el del despotismo es el temor.

Identificados la naturaleza y principios de cada forma de gobierno, procede el estudioso político a determinar cuál es el tipo de leyes que surgen de aquellos, y el sociólogo a describir las características culturales y las formas sociales y económicas que más se ajustan a cada una de ellas. Para la república aspectos como la educación, la frugalidad, el amor a la patria, que es la misma virtud, y la igualdad son fundamentales. El espíritu comercial es el que más favorece la forma de gobierno republicana, por ello es necesario que la mayoría de los ciudadanos lleven a cabo las actividades mercantiles. La monarquía requiere de poderes intermediarios como son la nobleza, el clero y las ciudades con sus privilegios e igualmente de un depósito de leyes porque, como hemos dicho, se trata del gobierno de uno solo pero con leyes fijas y preestablecidas. El honor, los privilegios, los rangos y, en general, la desigualdad, que el espíritu de moderación trata de corregir a través de las leyes, son características de la monarquía. La propiedad de la tierra y el usufructo de la misma es su forma económica por excelencia. El despotismo fundado en el temor no requiere de muchas leyes, hacer serviles a los hombres, inculcar el temor y algunos principios de religión muy simples resultan suficientes. Su característica económica son la pobreza y la inseguridad de las fortunas.

Pero el Barón de Montesquieu, a pesar de su rigor científico, no esconde su predilección por la forma de gobierno monárquica. Por ello en el libro XI de su obra magna, cuando se refiere a las leyes que forman la libertad política en relación con la constitución, tras definir la libertad como "poder hacer lo que se debe querer y en no estar obligado a hacer lo que no debe quererse"13, afirma que la democracia y la aristocracia no son estados libres por su naturaleza y que en los estados moderados (las monarquías) la libertad no se encuentra siempre, por cuanto sería necesario que no se abusara del poder; la experiencia enseña que siempre que hay autoridad se abusa de él. Por lo tanto, el poder requiere de límites que no los encuentra en el gobierno republicano, pero que pueden establecerse en el monárquico a través de la distribución de poderes.

11 Ibídem, p. 44.

12 Carlos Luis Secondat de Montesquieu. Del espíritu de la leyes. , México: Editorial Porrúa, 1973, p. 8.

13 lbídem, p. 103. 
La constitución inglesa cumple, para Montesquieu, con ese requisito, y por tanto, tiene por objetivo la libertad política. Por ello, dedica el capítulo VI del Libro XI, el más famoso de su obra, a la descripción de la forma de gobierno británico.

No obstante, haber sido Locke quien enunciara por primera vez la teoría de la separación de poderes y a pesar de que se afirma que lo que hace Montesquieu es plasmar lo expresado por aquel en su segundo ensayo sobre el gobierno civil, lo cierto es que la historia vincula El espíritu de las leyes y a su autor, con esta teoría fundamental para el derecho constitucional moderno. Por lo demás, existe una diferencia importante entre ambos autores en cuanto a la concepción del tercer poder.

No es el objeto del presente estudio describir en forma pormenorizada la teoría enunciada. Basta para nuestros fines destacar la forma maravillosa como describe el autor comentado los contrapesos que establece la Constitución inglesa para lograr el fin de la libertad política. Esos contrapesos se dan entre quienes se constituyen factores reales de poder en Inglaterra, a saber: el monarca, la nobleza y el pueblo (más concretamente la clase comerciante emergente].

El pueblo sólo toma parte en el poder eligiendo a sus representantes (cámara de los comunes], quienes tienen como función exclusiva hacer las leyes y fiscalizar la adecuada ejecución de las mismas. La nobleza (cámara de los lores) comparte con los representantes del pueblo la función legislativa, pero la ejerce en forma separada, porque si tuviera un voto como los demás, la libertad sería para ella esclavitud y no tendría interés en defenderla. En este esquema la nobleza desempeña un importante poder moderador entre el pueblo y el monarca. El cuerpo de nobles debe ser hereditario para que tenga interés en hacer preservar sus prerrogativas odiosas por sí mismas. La cámara de los comunes está facultada para estatuir y la de los lores para impedir.

El poder ejecutivo que exige siempre acción reside en el monarca por cuanto se desempeña mejor por uno sólo que por varios. El poder legislativo no tiene facultad de inmiscuirse en las actividades del ejecutivo pero sí tiene el derecho de examinar la forma cómo son ejecutadas las leyes que expide. Sin embargo, cualquier responsabilidad por la inadecuada ejecución de las leyes no puede recaer sobre el monarca sino sobre sus ministros.

Esta forma de separación y contrapeso de poderes constituye la mejor garantía para la libertad política dentro de un gobierno monárquico, que es el deseado por Montesquieu, con la condición de que sea despojado de los excesos que lo caracterizan en su época.

\section{LOS ECONOMISTAS}

Si la lucha de los pensadores precitados es contra el poder absolutista que arrebata a los individuos sus derechos más preciados de la libertad y la propiedad, la de los economistas clásicos es contra el estado mercantilista que, privilegiando ciertos intereses, actúa en contra del interés de los consumidores que es el único que debiera promoverse.

El sistema mercantil, en palabras de Adam Smith, considera que la riqueza del Estado está determinada por la cantidad de oro y plata que se tenga y que atesora estos metales es el camino más seguro para enriquecerse, por tanto, se hace necesario tener una balanza comercial favorable, para lo cual, el principal objetivo de la economía política es disminuir en lo posible la importación de bienes extranjeros para el consumo doméstico y aumentar la exportación de los productos nacionales.

Con el anterior objetivo en mente, el estado mercantilista adopta las siguientes medidas: establece elevados aranceles a los productos del exterior o prohíbe de manera definitiva 


\section{MISION JURIDICA}

ISSN 1794 -6OOXX NUMERO
enero - diciembre de 2009

la importación de los mismos; fomenta las exportaciones a través de la devolución de los gravámenes o impuestos que pesan sobre la industria cuyos bienes se exportan; otorga subsidios a los productos exportados o procura celebrar tratados ventajosos con otros estados.

Adam Smith dedica el libro IV de su obra a controvertir las prácticas del Estado mercantilista. Sostiene que tales medidas conllevan un monopolio doméstico a favor de los comerciantes y productores, en detrimento de los consumidores y que olvidan que si no es interferido el individuo al actuar en procura su beneficio y de la ganancia propia se inclina de una manera natural o necesaria a lo que resulta más útil para la sociedad, en otras palabras, es "conducido por una mano invisible a promover un fin que no entraba en sus intenciones" 14 sin que ello sea malo, ya que de esta manera promueve de mejor forma el interés de la sociedad, lo que tal vez no se lograría si formara parte de sus intenciones iniciales, pues, "No son muchas las cosas buenas que vemos ejecutadas por aquellos que presumen solo servir el interés público" 15 .

Por otra parte, nadie más que el propio individuo para determinar cómo puede invertir su capital de la mejor forma y "El gobernante que intentase dirigir a los particulares respecto de la forma de emplear sus respectivos capitales, tomaría a su cargo una empresa imposible y se arrogaría una autoridad que no puede confiarse prudentemente ni a una sola persona, ni a un senado o consejo, y nunca sería más peligroso ese empeño que en manos de una persona lo suficientemente presuntuosa e insensata como para considerarse capaz de realizar tal cometido" 16 .

También son objeto de crítica por parte de Smith las concepciones de los fisiócratas franceses que promueven una intervención del Estado a favor de la actividad agrícola considerándolos más inconsecuentes que los mercantilistas ${ }^{17}$.

La actuación del individuo debe por tanto quedar en perfecta libertad y el Estado solo tiene tres deberes que cumplir a saber:

- Proteger a los ciudadanos de la violencia o invasión extranjeras.

- Proteger a los ciudadanos de la violencia opresión de que pudieran ser víctimas por parte de otros estableciendo una recta administración de justicia.

- Erigir y mantener ciertas obras que no son de interés para los individuos ${ }^{18}$

Estos deberes del Estado justifican cierta intervención por parte de aquel y el establecimiento de mecanismos para la obtención de recursos encaminados a sufragar los gastos necesarios para su cumplimiento. Pero incluso en estas circunstancias, la intervención debe ser justificada y limitada, procurando en lo posible que tales gastos sean atendidos por los ciudadanos que se benefician en forma directa de las actividades estatales.

Tal es el caso de la administración de justicia que remonta su origen al del Estado. Coincide Smith con Locke en cuanto que la existencia de la propiedad y la necesidad de su protección justifican el gobierno civil ${ }^{19}$. En sus inicios, la administración de justicia era ejercida directamente por el soberano y antes que la causa de gastos para este era una fuente

14 Adam Smith, op. cit., p. 402

15 Adam Smith, op. cit., p. 402

16 Adam Smith, op. cit., p. 402

17 Adam Smith dedica el Capítulo IX, Libro IV de su obra al análisis de lo que denomina los sistemas agrícolas.

18 Adam Smith op. cit., p. 612

19 "El gobierno civil en cuanto instituido para asegurar la propiedad se estableció realmente para defender al rico del pobre, 0 a quienes tienen alguna propiedad civil contra los que no tienen ninguna." Op. cit., p. 633 
de ingresos. Las personas estaban dispuestas a pagar por la justicia y quienes resultaban vencidos en los procesos sufrían igualmente erogaciones económicas a favor del soberano. La separación de los poderes ejecutivo y judicial se explica por el incremento de los negocios en la sociedad como consecuencia del progreso. Pero en la medida en que la justicia dejó de ser administrada directamente por el soberano, delegando su ejercicio a funcionarios de rango inferior que debían ser pagados por su labor, se establecieron contribuciones a todos los ciudadanos para atender tales gastos de manera que no fueran las partes quienes los erogaran directamente previniendo de esta forma la corrupción. Desde ese momento se predica que la administración de justicia es gratuita. Tal separación resulta igualmente conveniente ya que "Cuando el poder judicial y el ejecutivo se mantienen unidos, es casi imposible que la justicia no se sacrifique a eso que vulgarmente se llama política". ${ }^{20}$ De la independencia del poder judicial dependen la libertad del individuo y su sensación de seguridad en la posesión de los derechos que le pertenecen y son pilares fundamentales del sistema de mercado.

De todas maneras, considera Smith que los gastos de la administración de justicia podrían fácilmente atenderse a través de aranceles judiciales sin riesgo de corrupción y aligerando las cargas públicas. Especie de tasa que sería sufragada en igual forma por todas las partes, administrada en forma independiente y distribuida entre los jueces. Como si estuviera pensando en Colombia, sugiere Smith que no pagando a los jueces hasta tanto los procesos se hubieran terminado "se excitaría la diligencia de los tribunales en la tramitación y fallo"21.

El establecimiento y sostenimiento de obras públicas por parte del Estado se justifica en la medida en que siendo muy útiles para la sociedad, dicha utilidad no podría compensar el costo que representan para un individuo o un grupo de personas, de manera que no es de esperarse que aquellos las realicen. Estas obras deben estar fundamentalmente encaminadas a facilitar el comercio como, por ejemplo, las carreteras, puentes o canales. Sin embargo, tampoco parece necesario que tales obras se costeen con rentas nacionales, sino que pueden ser administradas en forma independiente de manera que rindan una renta suficiente para absorber tales gastos. En los ejemplos citados, los gastos serían pagados en últimas por los consumidores que recibirían beneficios mayores a los costos asumidos. Las obras públicas que por su naturaleza no puedan producir renta para atender a su conservación, pero cuya conveniencia está limitada a un territorio o región determinada, deben ser sostenidas con cargo a rentas territoriales y no con cargo a las rentas de la nación.

No se pregunta Smith sobre cuál forma de gobierno es la más adecuada para la libertad de los hombres, simplemente quiere que este, sin importar la forma que adopte, realice las actividades que sirven a los propósitos del mercado mediante el cual los hombresconsumidores alcanzarán el bien público. El gobierno no es malo por ser monárquico sin separación de poderes o por ser aristocrático o democrático, es malo porque realiza las actividades que no le competen presumiendo servir el interés público 22.

\section{LOS TRIBUTOS, EL PODER PUBLICO Y EL MERCADO}

Establecido el papel del Estado para el liberalismo clásico inferimos una especial concepción de los tributos dentro de dicho Estado, una funcionalidad de los impuestos vinculada al poder público y al mercado. Teniendo en cuenta la estructura que hemos dado al presente escrito

20 Ibídem, p. 639.

21 lbídem, p. 636.

22 Resulta interesante hacer notar que Smith considera a la economía política como "una de las ramas de la ciencia del legislador 0 del estadista" sin importar mucho en cuál de lss dos quede radicada. Op. cit., p. 377. 
abordaremos el tema propuesto desde la óptica de los que hemos denominado los pensadores políticos y económicos.

\section{LOS POLITICOS}

1.1. A pesar de que como manifestamos en el aparte 1-1.1. de este escrito, John Locke realizó algunos escritos de carácter económico, para efectos de este análisis sólo tendremos en cuenta su ensayo sobre el gobierno civil.

Los impuestos se justifican por cuanto los gobiernos no pueden ser sostenidos sin grandes costos y todo aquel que quiera gozar de la protección del Estado debe contribuir con su sostenimiento.

Locke es fiel a la tradición del constitucionalismo inglés según el cual no puede haber impuestos sin representación ${ }^{23}$. Los impuestos no pueden ser establecidos sino con el consentimiento de los ciudadanos dado en forma directa o a través de los representantes por ellos escogidos. Si alguien pretendiera que tiene la facultad de establecer impuestos sin el consentimiento del pueblo invade el derecho fundamental a la propiedad y subvierte la finalidad del gobierno. Se pregunta Locke en forma conclusiva sobre el tema: "¿Qué clase de propiedad tengo si otro puede tener el derecho a tomarla cuando le plazca?"24.

2.2. Montesquieu dedica todo un libro (el XIII) del "Espíritu de las Leyes" al tema fiscal. Su título, aunque poco claro, enuncia el establecimiento de una relación entre tributación y libertad.

A partir de la clasificación de los sistemas tributarios en directos e indirectos se ha considerado que los primeros son más propicios que los segundos a la realización de los principios de equidad e igualdad. Similar distinción se realiza entre los impuestos que gravan la renta y los que recaen sobre el consumo.

Para Montesquieu las rentas de Estado "son una parte que da cada ciudadano de lo que posee para tener asegurada la otra, a para disfrutarla como le parezca"25.

Esta concepción de la renta estatal o de los tributos le sirve de base para sostener que estos no deben medirse por lo que el pueblo podría dar, sino por lo que debe dar, con lo cual se aparta del concepto de capacidad contributiva vinculado al principio de equidad. Adicionalmente, si la naturaleza es justa y recompensa en mayor forma a los laboriosos cuando un estado arbitrario los despoja de tales recompensas los arroja a la inacción ${ }^{26}$.

Afirma que el impuesto por cabeza (directo) es más propio de la servidumbre y que el impuesto sobre las mercaderías (indirecto al consumol se ajusta más a la libertad por cuanto no se refiere a las personas. Para que se tribute directamente es necesario ejecutar casa por casa repetidas investigaciones y nada puede resultar más contrario que esto a la libertad.

Los impuestos indirectos los siente menos el pueblo por cuanto no se le piden de una manera formal, ya que van incluidos en el precio de las mercancías. El vendedor, por su parte, colabora con el gobierno por cuanto sabe que no paga el impuesto, que la suma que anticipa por concepto del mismo la recuperará del comprador y que tiene asegurado el goce de su fortuna.

Es importante destacar cómo en Montesquieu anticipa un importante principio del sistema tributario atribuido universalmente a Adam Smith. Nos referimos al principio de eficiencia. Cuando explica las que leyes deben referirse al principio del gobierno en la monarquía señala que

23 Su origen se remonta a la Carta Magna del año 1215 en la cual Juan Sin Tierra debió aceptar que para establecer impuestos debía convocar a los obispos, arzobispos, abades, condes, barones y propietarios de tierras.

24 John Locke. Op. cit., p. 58.

25 Montesquieu. Op. cit., p. 140

26 Ibídem, p. 141. 
es indispensable cierto orden en la manera de imponer tributos para que la forma de cobrarlos no resulte más pesada que el tributo mismo y agrega que "El exceso de tributación produce un exceso de trabajo; ese exceso abruma; el cansancio origina la pereza." 27

La misma defensa de la tributación indirecta se basa fundamentalmente en la eficiencia de este tipo de impuestos. El impuesto directo por el contrario resulta difícil de determinar y de administrar prestándose incluso para la defraudación.

Tiene igualmente relación con el principio de eficiencia la forma de recaudación del tributo a través del arrendamiento, figura criticada por Montesquieu. El sistema del arriendo, muy utilizado desde los tiempos de Roma, consiste en ceder las rentas de los tributos a particulares a cambio de un precio que entregan al Estado. Para Montesquieu, el manejo directo de la recaudación es una manera de ahorrarle al Estado el aprovechamiento abusivo por parte de los arrendatarios quienes con el dinero que reciben ejercen un poder excesivo incluso sobre el mismo Estado, ya que, sin ser legisladores, imponen las leyes a su conveniencia.

\section{LOS ECONOMISTAS}

Para Adam Smith, la renta de la tierra, los salarios y los beneficios son la fuente originaria de toda clase de ingresos, razón por la cual, serán igualmente el objeto de la tributación bien sea individual o conjuntamente considerados ${ }^{28}$.

Según David Ricardo, en forma concreta, los impuestos siempre se pagan del capital o del ingreso del país ${ }^{29}$. Cuando después del cobro de un impuesto se aumenta la producción y se reduce el consumo, se entiende que aquel ha recaído sobre el ingreso, si, por el contrario, se disminuye la producción y aumenta el consumo, el impuesto recae sobre el capital. De todas formas, los impuestos no inciden necesariamente sobre el capital o sobre los ingresos porque graven aquel o a estos, lo cual depende más de la disposición y de las posibilidades del agente económico, quien con el fin de conservar su riqueza y posición social procurará pagarlos con cargo al ingreso, situación que debe ser igualmente propiciada por la política fiscal. ${ }^{30}$

Al igual que Smith, Ricardo considera como fuente de ingresos a la renta de la tierra, los salarios y los beneficios.

Pero no solamente son objeto de imposición los ingresos. En palabras de Adam Smith, cuando el Estado desconoce la manera de gravar directa y proporcionalmente a sus súbitos procura hacerlo en forma indirecta a través de sus gastos. La imposición al gasto se da principalmente por medio de los artículos de consumo ${ }^{31}$.

Esta misma posición es sostenida por David Ricardo, para quien los impuestos se recaudan disminuyendo los beneficios de los individuos o haciendo subir el precio de las mercancías en que se gastan tales beneficios ${ }^{32}$.

27 Ibídem, p. 39.

28 Adam Smith. Investigación sobre la naturaleza y causas de la riqueza de las naciones. 9a. Fondo de Cultura Económica, p. 726.

29 David Ricardo., Principios de Economía Política y Tributación. Editorial Sarpe, 1985, p. 137.

30 Ricardo, ob. cit., p. 139. A manera de ejemplo podemos decir que el impuesto al patrimonio recae sobre el capital si para su pago debemos disponer de uno 0 alguno de los bienes que lo conforman y no de los ingresos por la actividad que se realiza.

31 Smith, ob. cit., p.768.

32 Ricardo, ob. cit., p. 152. 


\section{MISION JURIDICA}

ISSN 1794 -6OOXX NUMERO
enero - diciembre de 2009

De todas maneras, Adam Smith señala unas "máximas" que deben aplicar a los tributos en general, de las cuales pueden derivar algunos de nuestros principios constitucionales de la tributación y que se resumen asi $^{i 3}$ :

a. - Los ciudadanos deben contribuir al sostenimiento del gobierno, en cuanto sea posible, en proporción a los ingresos que disfruten bajo la protección estatal (principio de capacidad).

b. - El impuesto que cada individuo está obligado a pagar debe ser cierto y no arbitrario. En palabras de Smith esta máxima es tan importante que, aun una desigualdad en el modo de contribuir, no acarrea un mal tan grande como la incertidumbre en cuanto a lo que se debe pagar (principio de legalidad).

c. - Todo impuesto debe cobrarse en tiempo y de la manera que sea más cómoda para el contribuyente (principio de eficiencia).

d. - Toda contribución debe percibirse de tal forma que haga la menor diferencia posible entre las sumas que salen del bolsillo del contribuyente y las que ingresan al Estado (principio de eficiencia).

A continuación resumimos las principales tesis de Adam Smith y David Ricardo en relación con las fuentes de la tributación y los impuestos que las caracterizan.

\section{A. LOS INGRESOS COMO FUENTE DE LA TRIBUTACION}

\section{La renta de la tierra}

Llama poderosamente la atención la importancia dada a este tema en las obras clásicas comentadas. Para cuando Smith escribe y publica su "riqueza de las naciones", Inglaterra asiste al surgimiento de la Revolución Industrial, por lo que en buena medida es considerado un precursor que con sus escritos contribuye a la destrucción del orden mercantilista y abre el camino a la forma de producción capitalista. Las tesis de Ricardo, en pleno furor en la Revolución Industrial, contribuyen también a derribar los vestigios del antiguo régimen.

La forma como los autores en estudio entienden la renta de la tierra difiere fundamentalmente. Para Smith la renta es el precio que se paga por el uso de la tierra, el cual no guarda relación con las mejoras realizadas por el propietario ni con lo que ésta pueda producir ${ }^{34}$. La renta será alta, baja o nula dependiendo de los precios de los bienes, los que a su vez estarán condicionados por el monto de los beneficios y de los salarios del trabajo. Conclusión de lo anterior es que la renta de la tierra no tiene incidencia en el precio de los bienes sino que, por el contrario, la primera está incidida por el segundo. Si el precio de los bienes es mayor, el agricultor pagará menos por concepto de la tierra. Los productos de la tierra constituidos por los alimentos para los seres humanos siempre proporcionan renta al dueño, mientras que otros productos pueden generar o no renta según las circunstancias ${ }^{35}$.

David Ricardo define la renta como "aquella porción del producto de la tierra que se paga al propietario por el uso de la potencia original e indestructible del suelo" ${ }^{36}$. La renta surge cuando

35 Dentro de este grupo señala Smith los productos necesarios para el vestido o para la vivienda respecto de los cuales la generación de renta depende de circunstancias como su situación, reservas, rendimiento o rareza. Ob. cit., p. 156 a 169.

36 Ricardo, ob. cit., p. 63. 
como consecuencia del crecimiento de la población se deben cultivar terrenos de inferior calidad. Cuando la tierra es muy abundante y productiva no produce renta. Si los terrenos de buena calidad fueran suficientes para la producción requerida por un país, o si gracias a los adelantos técnicos pudieran explotarse terrenos sin que se produjeran rendimientos decrecientes no habría lugar al aumento de la renta ${ }^{37}$.

De acuerdo con esta tesis, el precio de los bienes está determinado por los terrenos de calidad inferior por cuanto en ellos se requiere de una mayor cantidad de trabajo que determina su valor de cambio $^{38}$. Para Smith, en ciertas circunstancias y de manera inversa a lo planteado por Ricardo, la renta en terrenos incultos pudiera estar determinada por la de los terrenos productivos. ${ }^{39}$ Coinciden los autores comentados en cuanto a que la renta de la tierra no incide en el precio de los bienes, pero difiere en la medida en que, según la concepción ricardiana, la renta no puede ser objeto de determinación a voluntad por el agricultor en razón de los precios de los bienes.

La teoría de la renta de la tierra en la época de Ricardo fue un argumento importante en contra de la famosa "ley de granos", medida mercantilista que había establecido aranceles a la importación del trigo en Inglaterra. Con los argumentos de Ricardo se demuestra la inutilidad de la medida que encarece el valor del trigo ante la necesidad de cultivar tierras menos productivas e incrementa, en forma colateral, la renta de los propietarios.

\subsection{Impuestos vinculados a la renta de la tierra}

A partir de la concepción y alcance de la renta de la tierra Smith y Ricardo estudian los impuestos que están vinculados a esta fuente de ingresos a saber: el impuesto sobre la renta del suelo propiamente dicha, el impuesto sobre las casas y el impuesto sobre los productos del suelo que analizaremos a continuación.

\section{a. Impuesto sobre la renta de la tierra}

Explica Smith que este impuesto se establece con fundamento en una valoración que permanece inmodificada se cobra una cuota fija en forma periódica, o se determina teniendo en cuenta las variaciones que experimente la renta efectiva de la tierra. En el primer caso, el soberano no participa de las ganancias que pueda derivar el propietario como consecuencia de las mejoras que se produzcan en aquella.

El impuesto variable en razón de la modificación de la renta, comenta Smith, era el más recomendado por los fisiócratas franceses por ser el más equitativo y porque, según ellos, todos los impuestos se pagan en última instancia por la renta de la tierra, debiendo recaer sobre la fuente que en definitiva los absorbe. Sin embargo, este mecanismo no resulta de la entera satisfacción para el autor, por cuanto las eventuales variaciones de la renta harían más costosa la determinación y el cobro del impuesto, pero, fundamentalmente, porque limita el incentivo de progreso en el cultivo ya que "El terrateniente se mostrará menos dispuesto a hacer cierta clase de mejoras, si sabe que el soberano va a participar en el beneficio resultante de ellas sin haber participado en ninguna forma en los gastos" 40 .

Ante esta situación propone Smith como alternativa la exoneración del valor de las mejoras por cierto tiempo, suficiente para que el propietario recupere los gastos que determinaron

37 Ricardo, ob. cit., p. 67.

38 "Si la cantidad de trabajo empleada en las cosas regula su valor en cambio, cada incremento debe aumentar el valor del artículo a que se aplique, y del mismo modo, toda disminución debe reducirlo". Ricardo, ob. cit., p. 29.

39 Es el caso de terrenos incultos destinados a la cría de ganado en los que debido a que el precio de este se determina por el del criado en las tierras mejor cultivadas, los propietarios aprovechan esta circunstancia para elevar la renta. Smith. Op. cit., p. 144.

40 Smith, ob. cit., p. 733. 


\section{MISION JURIDICA}

ISSN $1794-600 \times$ NUMMERO
enero - diciembre de 2009 ?

las valorizaciones. Un tributo en estas condiciones podría establecerse como "disposición perpetua e inalterable, o sea como una de las leyes fundamentales del Estado".

Entendida la renta por David Ricardo como la porción del producto de la tierra que se paga al propietario por el uso de la potencia original e indestructible del suelo, el cobro de un impuesto sobre esta, debe distinguir la parte que se paga al propietario que es propiamente renta y la que remunera los edificios y demás obras realizadas por él y que conforman el capital. El tributo debe ser pagado exclusivamente por el uso de la tierra. El cobro por el uso del capital desincentiva al propietario impidiendo que el terreno se cultive hasta tanto se sufraguen con la renta las inversiones en capital y el impuesto cobrado. Esta parte del tributo es realmente un impuesto al capital que no recae sobre el agricultor o el propietario, sino sobre el consumidor por la vía del precio.

Por lo demás, considera Ricardo que el impuesto propiamente tal (excluido el gravamen sobre los edificios y demás obras] afecta únicamente al propietario sin que pudiera ser trasladado a los consumidores por cuanto, como se explicó anteriormente, la renta sobre la tierra no incide en el precio de los bienes producidos.

\section{b. Impuesto sobre la renta de las casas}

Adam Smith al referirse al impuesto sobre la renta de las casas distingue entre lo que denomina la renta del edificio y la renta del solar. La primera corresponde al beneficio que se origina en el capital empleado en edificar la casa y se regula normalmente por el interés corriente del dinero. La segunda corresponde a cualquier suma que exceda la anterior y remunera efectivamente el uso del suelo correspondiendo al propietario de este cuando se diferencia entre el dueño de la construcción y del terreno. La renta del solar la paga quien habita el inmueble por alguna ventaja real o supuesta relacionada con la ubicación del inmueble.

El impuesto sobre la renta del edificio se divide entre el inquilino y el dueño de la renta del solar -si recayera sobre el propietario de la construcción este se retiraría del negocio-, afecta en mayor medida, según opinión de Smith, a los ricos, sin que este trato desigual resulte desproporcionado, por cuanto se justifica que "el rico contribuya a pagar los gastos públicos, no sólo en proporción a sus ingresos sino de una manera algo más que proporcional." 41 Adicionalmente mientras que la renta sobre la tierra se paga sobre el uso de un bien productivo, la del edificio afecta un bien improductivo.

Aunque incluimos este impuesto dentro de la renta de la tierra, en la medida en que es pagado por el arrendatario su fuente está vinculada al canon pagado, pudiendo provenir de los salarios, los beneficios del capital o de renta de la tierra, asimilándose más su naturaleza a un tributo sobre los artículos de consumo. Las casas no arrendadas no deben pagar el impuesto por cuanto equivaldría a gravar al dueño sobre una cosa que no le produce renta.

El impuesto sobre la renta del solar recae plenamente sobre el dueño de la renta de la tierra, ya que si estuviera a cargo del inquilino, estaría menos dispuesto a pagar por el uso del suelo. Por supuesto, las casas sin habitar tampoco pagan este tributo.

En concepto de Smith, resulta más apropiada y razonable la imposición de la renta sobre los solares edificados que la renta corriente de la tierra, ya que aquella se debe en mayor medida a la buena administración del gobierno.

Para David Ricardo, por su parte, el impuesto sobre las casas aunque se cobre al ocupante recae sobre el propietario a través de la disminución de la renta, ya que de lo contrario se considera como una renta adicional a cargo del inquilino con la consecuente disminución la

41 Smith, ob. cit., p. 742. 
demanda de casas en alquiler sin disminuir su oferta. En estas condiciones la renta baja y parte del impuesto es pagado indirectamente por el propietario.

Ricardo está en desacuerdo con este impuesto por cuanto grava exclusivamente un grupo particular de ciudadanos, y las cargas del Estado deben ser soportadas por todos en proporción a sus medios. Considera igualmente que "La renta pertenece a los que después de varios años de trabajo han realizado sus ganancias y gestado sus fortunas en la compra de terrenos o de casas; y ciertamente someterles a una tributación desigual es infringir aquel principio que debiera considerarse como sagrado: la seguridad de la propiedad. " 42

\section{Impuestos sobre el producto del suelo}

El diezmo constituye el ejemplo paradigmático de un impuesto sobre los productos del suelo y a él se refiere principalmente Smith en su escrito, señalando que esta clase de gravámenes recae fundamentalmente sobre la renta de la tierra y aunque los pague el agricultor, quien en últimas debe sufragarlos es el propietario de aquella. Los considera impuestos desiguales a pesar de su aparente uniformidad, ya que la renta para los diferentes agricultores varía dependiendo, entre otras circunstancias, de la productividad de la tierra.

Pero la objeción más importante constituye, para el autor comentado, el hecho de que impuestos de esta naturaleza desincentivan la actividad económica inhibiendo al propietario de realizar mejoras sobre los predios y haciendo descuidado el cultivo por parte del agricultor a sabiendas de que cuanto más rinda la tierra mayor será el impuesto cancelado.

Los impuestos sobre el producto del suelo, en términos de David Ricardo, harían subir el valor de los productos gravados recayendo sobre los consumidores de los mismos y no sobre el propietario de las tierras como explica Smith. Si se trata de bienes de primera necesidad conllevarían un incremento de los salarios de los trabajadores para quienes dichos bienes son parte integral de su subsistencia, que afectan consecuentemente los beneficios del agricultor y del industrial que deben pagar los salarios de aquellos.

Ahora bien, cuando el impuesto recae sobre los consumidores, grava a todos por igual, pero cuando afecta los beneficios es desigual, ya que no afecta las rentas de los propietarios, ni los beneficios del capitalista, quienes sólo pagan este impuesto en cuanto tengan la calidad de consumidores. Ante esta desigualdad del impuesto propone Ricardo que el legislador grave directamente las rentas de quienes por la naturaleza del tributo no están cubiertos por el mismo.

Por otra parte, podría argumentarse que al afectar este impuesto a los trabajadores en su condición de consumidores, el tiempo que transcurre entre el incremento del precio de los bienes de primera necesidad y el incremento salarial, los hará padecer dificultades y miseria. David Ricardo desestima esta apreciación explicando que el precio de los bienes de primera necesidad proviene de causas muy diferentes siendo apenas una de ellas el establecimiento de un impuesto sobre los mismos. Fundamentalmente, las leyes de la oferta y la demanda nivelan la situación rápidamente. Así, por ejemplo, si un impuesto sobre el trigo hace subir su precio, sin que en forma inmediata se incrementen los salarios de los trabajadores, el hecho de que estos no puedan adquirirlo disminuye la demanda haciendo necesariamente caer los precios a niveles que pudieran ser nuevamente adquiridos por los trabajadores. El riesgo entonces para los trabajadores por esta clase de gravámenes se limita a la posibilidad de que disminuir los fondos destinados a la subsistencia de los trabajadores reduce consecuentemente la demanda de mano de obra.

42 Ricardo, ob. cit., p. 183. 


\section{MISION JURIDICA}

ISSN $1794-60$ Y CIENCIAS SOMERO

Se argumenta también en contra de esta clase de impuestos que, al hacer subir el precio de los bienes (los que provienen de la tierra y los que tienen en su composición productos de la tierra) los haría menos competitivos en el comercio exterior. Objeción que disuelve también Ricardo a partir de las leyes de la oferta y la demanda. Una situación como la planteada, al encarecer la producción nacional, favorece la importación de productos extranjeros más competitivos. La adquisición de los productos extranjeros disminuye las cantidades de metálico en el país importador haciendo subir su precio y por esta vía permite la exportación de los productos nacionales que habrían recobrado su valor como consecuencia de la exportación de la moneda.

\section{Los salarios}

El salario del trabajo es para Smith “'... ) aquella recompensa que se otorga cuando el trabajador es una persona distinta del propietario del capital que emplea al obrero." 43 El propietario del dinero no está dispuesto a ocupar al trabajador a menos que tuviera una participación en el producto de aquel. Los trabajadores van a estar siempre interesados en incrementar su salario y los patronos en rebajarlo. Sin embargo, existe cierto nivel por debajo del cual no pueden disminuir ya que los salarios deben ser suficientes para permitir al obrero vivir de su trabajo.

David Ricardo lo explica en una forma más precisa y contundente: el trabajo tiene un precio natural y un precio de mercado; el precio natural "es aquel necesario para permitir a los trabajadores subsistir y perpetuar su raza sin aumento ni disminución." 44 . El precio natural del trabajo depende entonces del precio de los alimentos y de las cosas necesarias y convenientes para el sostenimiento del trabajador y de su familia. El precio de mercado del trabajo es lo que se paga realmente por él y está determinado por la ley de la oferta y la demanda. En virtud de dichas leyes el precio de mercado del trabajo podría ser inferior al precio natural, lo que haría muy difícil la situación del trabajador.

Según los dos autores comentados las leyes del mercado son inexorables para los trabajadores. Expone Smith que el aumento de la demanda de mano de obra sólo puede producirse con el incremento del ingreso y del capital de las naciones que equivale al incremento de la riqueza nacional. Pero no es la magnitud real de la riqueza de una nación lo que motiva el aumento de los salarios, sino su continuo incremento, por lo tanto, los salarios más altos no se encuentran en los países más ricos, sino, en los más laboriosos y en los que más rápidamente se enriquecen ${ }^{45}$.

En términos de Ricardo, el capital puede aumentar en cantidad y en valor cuando, por ejemplo, aumentan los bienes producidos y la cantidad de trabajo necesario para producirlos. Puede también producirse un aumento de capital sin incremento del valor, cuando en virtud de las mejoras tecnológicas se producen más bienes sin incrementar la cantidad de trabajo necesario. En la primera circunstancia, el precio natural de la mano de obra se incrementa y en el segundo permanece estacionario o baja, sin embargo, en ambos casos el precio de mercado del trabajo se incrementa en la medida en que aumenta la demanda de mano de obra siendo igualmente superior al precio natural.

Si a los elementos de análisis anteriores agregamos la concepción Maltusiana presente en Ricardo, el panorama para la clase trabajadora resulta desolador. El crecimiento cada vez mayor de la población frente a unos recursos limitados, muy a pesar de la potencial productividad, determina que por un lado disminuya la demanda de mano de obra y por el otro, los artículos de primera necesidad suban como consecuencia de la presión de la demanda sobre estos. El

43 Smith, ob. cit., p. 65.

44 Ricardo, ob. cit., p. 87.

45 Smith, ob. cit., p. 68. 
incremento de la cantidad de trabajo necesario para la producción de los bienes incrementará el valor de mercado del trabajo, pero no en forma suficiente que permita al trabajador adquirir la misma cantidad de artículos necesarios para su subsistencia. Ante esta situación las únicas soluciones son la reducción de la población o una ocupación más rápida del capital, no siendo esta última solución posible en los países donde ya toda la tierra fértil ha sido cultivada.

De poco sirven las leyes de pobres tan en moda en la época de Ricardo, para quien, a pesar de las buenas intenciones del legislador, antes que mejorar la condición de los desvalidos, empeoran su situación y la de los ricos, de manera que según su opinión "(...) la comodidad y bienestar de los pobres no pueden quedar asegurados de un modo permanente sin algún esfuerzo de estos, o de la legislatura, que venga a regular el incremento de su número, y a hacer que sean menos frecuentes entre ellos los casamientos tempranos e imprevisores. "46 La observación de Smith sobre este particular resulta más dura y realista: "Todas las especies animales se multiplican en proporción a los medios de subsistencia, y no hay especies que puedan hacerlo por encima de esa proporción. Pero en una sociedad civilizada sólo entre las gentes de los rangos inferiores del pueblo la escasez de alimentos puede poner límites a la multiplicación de la especie humana; y esto no puede ocurrir de otro modo que destruyendo una gran parte de los hijos, frutos de fecundo matrimonio." 47

Concluye David Ricardo su análisis sobre los salarios, en los siguientes perentorios términos: "Esas son pues, las leyes por las cuales se regulan los salarios y se rige la felicidad de la mayoría de los componentes de la comunidad. Como todos los demás contratos, el ajuste de los salarios debe dejarse a la libre concurrencia del mercado y no debe nunca ser controlado por medio de leyes" 48 .

\subsection{Impuestos sobre los salarios}

Considera Adam Smith completamente desaconsejable un impuesto sobre los salarios. Resulta poco probable que aunque el monto del impuesto lo pagara directamente el trabajador, este estuviera a su cargo. En condiciones normales de mercado, el impuesto daría lugar a un incremento del salario, lo que haría que el industrial se sintiera autorizado para cargar dicho incremento en sus mercancías con su correspondiente beneficio, debiendo en últimas asumir el impuesto el consumidor. Tratándose de obreros empleados en la agricultura, el incremento de los salarios vendría en detrimento del propietario quien vería reducida su renta sobre la tierra. En estas condiciones el impuesto del trabajador sería pagado finalmente por los propietarios de la tierra y por los consumidores.

En oposición a lo sostenido por Smith, Ricardo es de la opinión que un impuesto sobre los salarios afecta los beneficios. En este sentido el impuesto sobre los salarios se asimila al que recae sobre los artículos de primera necesidad y no produce menoscabo ni al capitalista Centendido como aquel que deriva beneficios vía rendimientos del dinero o mediante dividendos en acciones], ni al propietario de la tierra, ni al consumidor, sino solamente, a quienes empleen trabajadores.

En opinión de Ricardo la tesis de Smith resulta insostenible, por cuanto si el industrial traslada el incremento de los salarios en el valor de las mercancías que produce, el trabajador es a su vez consumidor de dichas mercancías lo que haría nuevamente aumentar el valor de los salarios y " (...) la acción y reacción de los salarios sobre las mercancías, y luego la de estas sobre aquellos, irían produciéndose sucesivamente, sin que pueda asignársele límite

46 Ricardo, ob. cit., p. 98.

47 Smith, ob. cit., p. 79.

48 Ricardo, ob. cit., p. 96. 


\section{MISION JURIDICA}

ISSN $1794-600 \times$ NUMERO
enero - diciembre de 2009 ?

alguno. "49 Lo mismo puede sostenerse de la situación que se produciría entre los diferentes industriales, quienes tratarían de resarcirse del valor del impuesto incrementando el precio de sus mercancías, pero que al ser a su vez consumidores de las mercancías producidas por los otros estarían pagando también en las mercancías adquiridas el valor del impuesto sin que este pudiera compensarse nunca.

\section{Los beneficios del capital}

Ni Smith, ni Ricardo definen en forma precisa "los beneficios", como sí lo hicieron con los otros elementos del ingreso (la renta de la tierra y los salarios).

Smith dice en un aparte de su obra que cuando se cambia una mercancía por dinero, por trabajo o por otra mercancía, además del pago de los materiales utilizados y los salarios de los trabajadores, es necesario que se dé algo a título de las ganancias que le corresponden al empresario que comprometen su capital en la producción de la mercancía. ${ }^{50}$ Agrega más adelante que parte del beneficio paga el interés correspondiente al capital y otra los riesgos y las molestias en que incurre el empresario ${ }^{51}$.

Para Ricardo, todo valor de las mercancías se divide en dos porciones: una constituye los beneficios de capital y otra los salarios del trabajador ${ }^{52}$. El monto de los beneficios está, por lo tanto, condicionado por el valor de los salarios. No toda alza del valor de los productos afecta los beneficios, sólo aquella que conlleva un incremento de los salarios. Un incremento en el valor de los productos de primera necesidad acarrea un aumento de los salarios y por tanto una disminución de los beneficios. No sucede lo mismo con los artículos de lujo los cuales al no ser consumidos por el trabajador no afectan su salario.

A pesar de las reglas anteriores que determinan el aumento o disminución del beneficio, advierte Adam Smith que este es fluctuante, y que ni siquiera el dueño de un negocio está en capacidad de informar cuál es su beneficio anual promedio. Observa sí, la existencia de cierta relación entre los beneficios y el interés corriente, aumentando aquellos cuando este sube y disminuyendo en caso contrario.

\subsection{Impuestos sobre los beneficios del capital}

A partir de la división que hace Smith de los beneficios, una parte remunerando el capital y la otra las molestias y riesgos del empresario, es enfático al afirmar que esta última parte del beneficio no puede de ninguna manera ser objeto de imposición. Si el empresario no recibe esta compensación prefiere dejar el negocio. Si se decide por incrementar su beneficio para recuperar el impuesto pagado, este es en últimas sufragado por el propietario de la tierra, si el capital se aplica a la agricultura, o por el consumidor, si es destinado a la actividad comercial o manufacturera. En último recurso, el empresario podrá trasladar el impuesto al capitalista que le hubiera facilitado los recursos disminuyendo la tasa de interés.

El interés del dinero, en cambio, parece, a criterio de Smith, tan fácil de gravar como la renta de la tierra. Es un producto neto que queda después de compensar el riesgo y las molestias del capitalista y el impuesto no puede hacer subir la tasa de interés ya que la cantidad de capital en el país no varía con ocasión del cobro del impuesto. Sin embargo, obran en contra de su idoneidad las siguientes circunstancias: la dificultad de determinar la cantidad de capital en cabeza de sus dueños y la facilidad de su desplazamiento. Sobre este particular

49 Ricardo, ob. cit., p. 203

50 Smith, ob. cit., p. 48.

51 Smith, ob. cit., p. 746.

52 Ricardo, ob. cit., p. 101 
las palabras de Smith gozan de especial actualidad en nuestro mundo globalizado "El dueño del capital es propiamente ciudadano del mundo y no se encuentra necesariamente vinculado a una determinada nación. Se halla en condiciones de abandonar el país que le someta a un trato vejatorio, para gravarle con una contribución molesta, trasladando su capital a otras tierras donde pueda ejercer la industria y disfrutar su patrimonio con más tranquilidad. " 53 El impuesto resulta entonces contraproducente ya que, antes que ser una fuente de recursos, contribuye a la pérdida de capitales que de otra manera se utilizan en las actividades productivas del país.

Por otra parte, explica Smith que si son objeto de imposición ciertos negocios particulares, el tributo recae necesariamente sobre los consumidores, ya que, en todo caso el empresario debe percibir un beneficio razonable y donde la competencia es libre solo puede existir una ganancia de esta especie. En estas circunstancias los empresarios solo comercian los productos cuyos precios puedan absorber los montos que deban pagar por el impuesto o de lo contrario retiran parte del capital del negocio. Si los recursos están invertidos en la agricultura el monto del gravamen se desplaza al propietario de la tierra a través de la disminución de su renta. Las tesis expuestas por Smith sobre este particular no son compartidas por David Ricardo para quien, un impuesto sobre los beneficios bien gestionado no afecta el valor de las mercancías y por ende a los consumidores ${ }^{54}$.

Explica Ricardo que si se gravan todas las industrias con un impuesto proporcional, todos los artículos suben de precio, pero que si las minas que proveen el metal para la moneda estuvieran en el país y se grava también el beneficio del minero, ningún artículo sube de precio, cada quien da una proporción igual de su renta y todo queda igual que antes.

Sin embargo, como el dinero es una mercancía importada, los precios de todas las mercancías no pueden subir sin que exista la suficiente cantidad de circulante para pagarlas y eéste no podría obtenerse a cambio de mercancías costosas. De manera que una subida generalizada de las mercancías no puede ser permanente sin afectar el comercio exterior lo que ocasiona mayores importaciones hasta tanto las mercancías nacionales disminuyan su precio.

\section{B. EL GASTO COMO FUENTE DE TRIBUTACION}

Como manifestamos atrás para Smith el tributo sobre el gasto se presenta a través de los artículos de consumo que se clasifican en necesarios y de lujo.

Los artículos necesarios son aquellos indispensables para el sustento de las personas o cuya falta resulta indecorosa para cualquier individuo. Son artículos de lujo todos aquellos que no puedan ser tenidos como necesarios. Smith advierte que la denominación "artículos de lujo" no implica reproche al empleo moderado de los estos.

Un impuesto sobre los artículos necesarios al incrementar su valor sube los salarios contrariamente a lo que sucede cuando la imposición se establece sobre los artículos de lujo, ya que no afectan la capacidad de los trabajadores para su sostenimiento y el de sus familias. Por otra parte, los impuestos sobre los artículos de lujo no tienden a elevar el precio de las demás mercancías, lo que sí acontece con el gravamen sobre los artículos de primera necesidad que al incrementar los salarios encarecen los demás artículos lo que afecta su consumo.

En las circunstancias expuestas entiende Smith que un tributo sobre los artículos de primera necesidad recae directamente sobre el propietario de la tierra y sobre los consumidores, advirtiendo que "Si las clases superiores y medias del pueblo tuviesen

53 Smith, ob. cit., p. 748.

54 Ricardo, ob. cit., p. 193. 


\section{MISION JURIDICA}

ISSN 1794 -6OOXX NUMERO
enero - diciembre de 2009

conciencia de sus intereses, se opondrían siempre al establecimiento de impuestos sobre los artículos de primera necesidad y de gravámenes directos sobre los salarios de trabajo. El pago definitivo de ambos impuestos recae siempre en ellas y siempre con una sobrecarga considerable. "55 Señala cómo a pesar de las consecuencias adversas de este tipo de impuestos, el Gobierno insiste en ellos por cuanto le proporcionan un ingreso considerable que no es fácil de obtener por otros mecanismos.

El impuesto sobre los artículos de lujo de calidad inferior ${ }^{56}$, en cambio, constituye una fuente de ingresos importantes por cuanto recaen en toda la población, y el consumo de las clases inferiores es mucho mayor en cantidad y valor que el de las clases medias y superiores, así individualmente sea considerado pequeño.

Ricardo coincide con Smith en cuanto a los efectos de los impuestos sobre los artículos de lujo, pero en cuanto a los artículos de consumo necesario, consistente con sus posiciones en relación con el impuesto sobre el salario y sobre los productos del suelo, entiende que sus efectos recaen igualmente sobre los beneficios del capitalista.

\section{CONCLUSIONES}

1. El liberalismo clásico desde su corriente política y económica constituye una defensa del individuo-consumidor frente al poder opresor del monarca absolutista o del estado mercantilista que fomenta los intereses egoístas de productores y comerciantes y no el de los consumidores que resultan olvidados por completo.

2. La finalidad del Estado liberal es la protección de la libertad y la propiedad de los individuos, sus derechos más preciados en el estado de naturaleza y que justifican su ingreso al estado de sociedad.

3. La existencia del estado de sociedad justifica el cobro de los tributos pero los mismos no pueden ser impuestos sin el consentimiento del pueblo en forma directa o a través de sus representantes.

4. Para Montesquieu los impuestos directos son más propios de la servidumbre mientras que los indirectos se ajustan más a la libertad.

5. Adam Smith y David Ricardo reconocen la posibilidad de que los impuestos recaigan sobre el ingreso o sobre el gasto, pero David Ricardo resulta más enfático en considerar la imposición sobre los ingresos más convenientes y ajustados a las leyes del mercado.

6. Adam Smith privilegia el impuesto sobre la renta de la tierra y sobre la renta de las casas bajo la condición de que el Estado no participe de ninguna forma de los beneficios obtenidos gracias a la iniciativa privada y que el gravamen de ninguna manera la desestimule. David Ricardo se opone a ellos con el argumento que desconocen el sagrado derecho a la propiedad.

7. Mientras que Smith se opone abiertamente a los impuestos sobre los beneficios, Ricardo considera que bien gestionados deben ser la forma de tributación por excelencia.

55 Smith, ob. cit., p. 772

56 Se refiere, por ejemplo, al impuesto sobre la cerveza. 
8. Para ambos autores constituye un elemento fundamental de apreciación de los tributos la conformidad o no de los mismos con las leyes del mercado y el hecho de que no las obstruyan.

9. Adam Smith se opone a los impuestos sobre los salarios no con base en argumentos de justicia o equidad, sino fundamentalmente de conveniencia por cuanto el impuesto afecta en últimas a los propietarios de la tierra y a los consumidores.

10. El énfasis del análisis de Smith y Ricardo en materia fiscal está puesto fundamentalmente en la supremacía de la iniciativa privada y en la eficiencia de los tributos.

\section{BIBLIOGRAFIA}

Dunn, John. Locke. New York: Oxford University Press, 1984.

Locke John. "Concerning civil Government". Great Books of the Western World, Encyclopedia Britannica, Inc, 33, 1991.

Ricardo, David. Principios de Economía Política y Tributación. Madrid: Editorial Sarpe, 1985.

Secondat de Montesquieu, Carlos Luis. Del espíritu de la leyes. México: Editorial Porrúa, 1973.

Smith, Adam. Investigación sobre la naturaleza y causas de la riqueza de las naciones. 9a reimpresión. México: Fondo de Cultura Económica, 1997. 